\title{
HYPERMETHYLATED DNA AS BIOMARKER FOR NASOPHARYNGEAL CANCER DETECTION
}

\author{
THUAN DUC LAO ${ }^{1}$, THUY AI HUYEN LE ${ }^{2 *}$
}

${ }^{1}$ Department of Molecular and Environmental Biotechnology, Faculty of Biology and Biotechnology, University of Science, Vietnam National University Ho Chi Minh City, Vietnam. ${ }^{2}$ Department of Pharmaceutical Biotechnology, Faculty of Biotechnology, Ho Chi Minh City Open University, Ho Chi Minh City, Vietnam. Email: thuy.lha@ou.edu.vn

Received: 21 June 2017, Revised and Accepted: 24 May 2018

\begin{abstract}
Background: Nasopharyngeal carcinoma (NPC) is a malignancy with remarkable geographic and distribution worldwide, towards in Southern China and Southern Asia. In addition to Epstein-barr virus infection, environmental carcinogens, the development of NPC involves the cumulative genetic as well as epigenetic alteration. More recently, it has been reported that DNA hypermethylation, an epigenetic mechanism, that occurred by the addition of a methyl group at 5' position of the pyrimidine ring of Cytosine residues at CpG islands, has been considered as the cause of nasopharyngeal tumorigenesis. In recent years, many reports have focused on the identification, evaluation of aberrant methylation of target tumor suppressor genes' promoters, such as RASSF1A, Blu, DLEC, RAR $\beta, p 16, p 15, p 14, M G M T$, etc. in the NPC development.
\end{abstract}

Objective and Method: In this review, we summarized and focused on the description and exemplification of the DNA hypermethylation changes, particularly, highlight the DNA hypermethylation as a potential biomarker applied in monitoring, screening, early diagnosis for cancer of nasopharynx.

Conclusion: Measuring and detecting the hypermethylation status of TSGs could be served as potential, and promising biomarkers for monitoring, early screening and diagnosis of human cancers.

Keywords: DNA hypermethylation, Epigenetic, Tumor suppressor gene, Biomarkers.

(C) 2018 The Authors. Published by Innovare Academic Sciences Pvt Ltd. This is an open access article under the CC BY license (http://creativecommons. org/licenses/by/4. 0/) DOI: http://dx.doi.org/10.22159/ajpcr.2018.v11i9.20974

\section{INTRODUCTION}

Nasopharyngeal carcinoma (NPC), arises from the epithelium of the nasopharynx, is the most common malignant tumor of head and neck cancer with a remarkable geographic and racial distribution worldwide [1-3]. There is a striking distribution of NPC, which encounters in Southern China, Singapore, Vietnam, Malaysia, and the Philippines. On the contrary, it is also fairly common in Europe, USA, Northwest Canada, and Greenland [1,4,5]. According to the etiological factors of NPC, many previous studies suggested that there are several cofactors that are associated with NPC development. The major etiological factors proposed for NPC pathogenesis include the dietary factors, the infection with an oncovirus, named Epstein-Barr virus (EBV), a gamma herpes virus discovered in 1964 by Epstein et al. $[5,6]$, and genetic-epigenetic factors, in a multistep carcinogenic process $[3,7,8]$. The remarkable racial and geographic distribution of NPC suggests the strong association of NPC with genetic susceptibility and environmental factors [7]. Based on the previous studies, a collaborative model for NPC tumorigenesis driven by specific genetic alteration, EBV infection, and environmental factors is proposed (Fig. 1). The viral risk factors and environmental factors for NPC discussed separately in many previous studies; therefore, this article will focus primarily on the epigenetic alterations, including the promoter hyper methylation, in NPC tumorigenesis.

\section{DNA HYPERMETHYLATION AND CANCER}

In contrast to the genetic alterations, epigenetic regulations, which were first coined by Waddington in 1942, means as "outside conventional genetics," refer to the heritable, reversible changes in gene expression that does not change the sequence of genome [9]. Recent advances in the field of epigenetics have shown that epigenetic modification is the natural processes and essential formammalian development and cell proliferations that affect gene products at multiple levels, including transcriptional level, post-transcriptional regulation, leading to the great diversity to the gene regulation network $[9,10]$. In the case of improperly occurred, they could be the major cause of health and normal development. Three main types of epigenetic modification systems, including DNA methylation, histone covalent modification, and non-coding RNA modification, leading to associated-gene disrupted, have been identified [11-13]. The pattern of hypermethylation, one of the two aberrant methylations, at the specific sites, namely, the CpG islands (CGIs) at the tumor suppressor genes (TSGs)' promoter region, leads to the increasing of level of methyl group modification, is an important mechanism of a number of TSG inactivation [14-17]. This methylation process is catalyzed by DNA (cytosine-5)methyltransferases (DNMTs). In mammalian, DNMTs are a highly conversed family protein encompassing DNMT1, DNMT2, DNMT3A, DNMT3B, and DNMT3L, which could be distinguished by their function [18-20]. DNMT1, which functions as the major maintenance of the existence of methylation patterns following DNA replication on the newly synthesized, was the first methyltransferase to be discovered. DNMT3A and DNMT3B perform de novo methylation by adding the methyl groups to unmethylated $\mathrm{CpG}$, which is responsible for the establishment of new methylation pattern in genomic [20-22]. DNMT3L has no catalytic activity, and it has been shown to act as a general stimulatory factor for de novo methylation and facilitate methylation of DNMT3A and DNMT3B [23-25]. The hypermethylated CGIs at promoter region prevent the binding of RNA polymerase and transcription factors, such as AP-2, c-Myc/Myn, E2F, and NF- $\kappa B$, as the results inhibit the TSGs transcription [10,20] (Fig. 2). The hallmark of cancer involves the loss of the function of TSGs through the silencing genetic information. The silencing of TSGs by the high levels of 5-methylcytosine in their CGI promoter regions, considered as the "first and second hit," is equivalent to mutation and translocations, in Knudson's two-hit model of tumorigenesis [26,27]. Thus, the presence of m5CpG dinucleotide in TSGs' promoters is recognized as an important event in many human cancers.

\section{DNA HYPERMETHYLATION IN NPC: BIOMARKERS FOR NPC DIAGNOSIS AND PROGNOSIS}

Previous studies suggested that NPC is associated with the accumulation of many epigenetic alterations on the particular chromosomal regions 


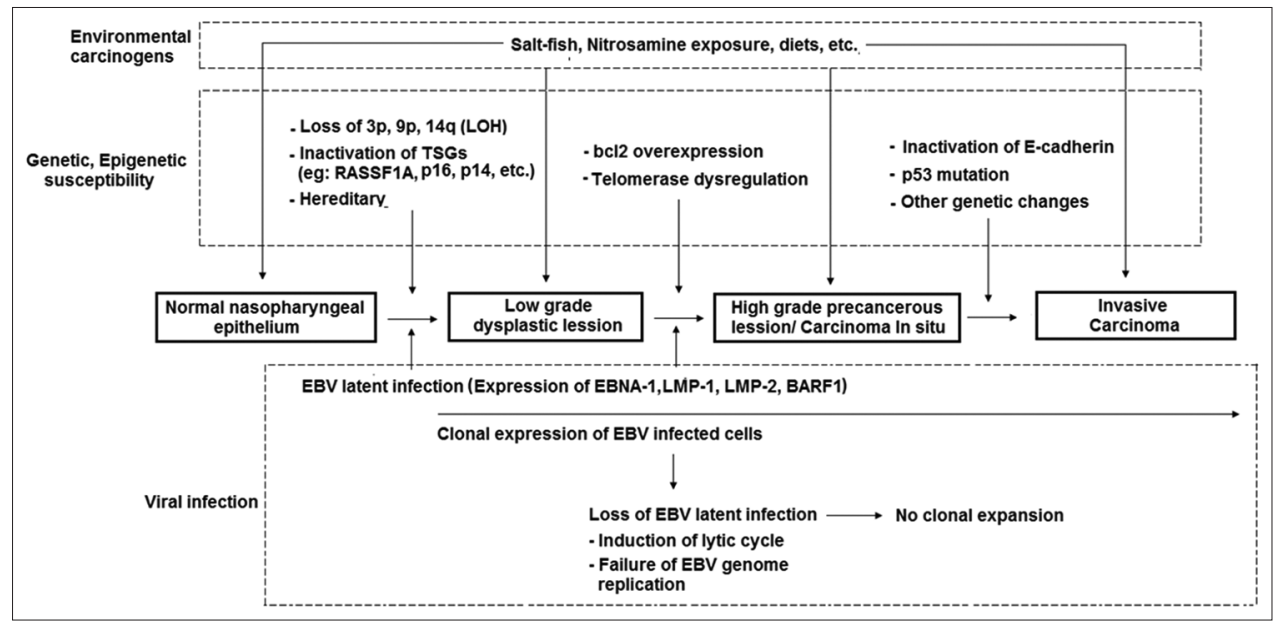

Fig. 1: Pathogenesis model for nasopharyngeal carcinoma

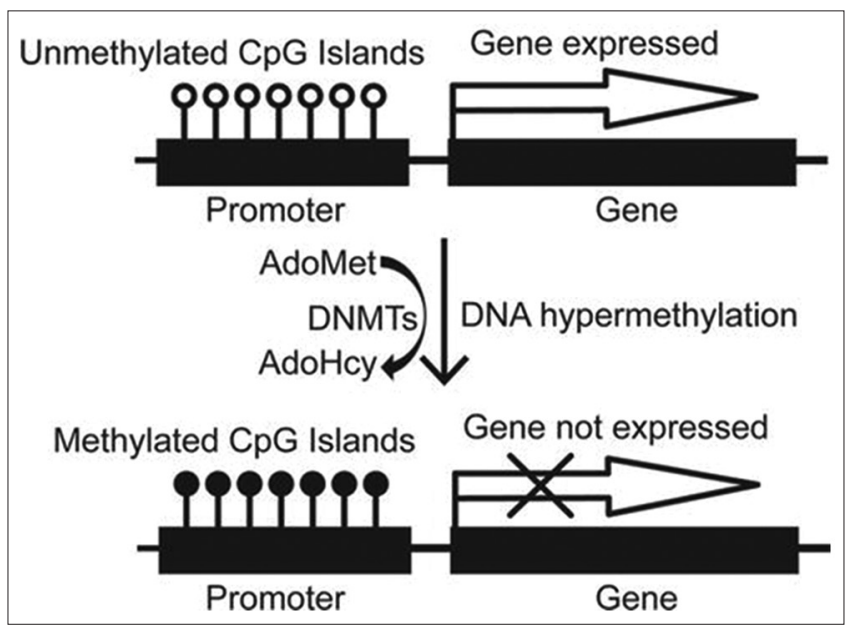

Fig. 2: The typical $\mathrm{CpG}$ island of a tumor suppressor gene is represented in a normal and a tumor cell [20]. White dots:

Unmethylated CpG; black dots: Methylated CpG. AdoMet: S-adenosylmethionine. AdoHcy: S-adenosylhomocysteine. DNMTs: DNA (cytosine-5)-methyltransferases

and genes, including the alterations involve both TSGs and protooncogenes on multiple cellular pathways, which further contribute to the malignant cancer hallmarks $[2,8,10]$. Interestingly, recent studies confirm that epigenetic alterations, including the hypermethylation, are also one of the crucial factors that are highly associated with NPC development. According to the research of Dai et al., in their comparative methylome study, as the compared to nine other human cancer types, including liver, head and neck, colon, lung, thyroid, kidney, breast, pancreatic, and prostate cancer, they found that NPC had the highest hypermethylation frequency [28]. Many studies demonstrated that the inactivation of TSGs located on chromosome 3p, 9p, 9q, 11q, $13 q, 14 q$, and $16 q$ is the common and important events in the NPC tumorigenesis and development, as summarized in Table 1 [8,29-32]. Representatively, the most frequently hypermethylation is reported in critical regions on chromosome 3p in NPC, as noted in Table 1.

Previous studies have shown that the inactivation of TSGs, which were located in chromosome 3, was significant associated with the development of NPC. Given the aberrant methylation frequently observed in NPC, we, therein, evaluated the status of methylation biomarkers for NPC detection, as summarized in Table 2. Based on Table 2, it suggested that ZMYND10, RASSF1A, DLEC1, and RAR $\beta$ promoter hypermethylation are more frequent in NPC than in noncancerous samples. Given examples, the well-known suppressor gene,
RASSF1A, located at 3p21.31, according to the systematical analysis of RASSF1A promoter methylation in NPC, Ye et al. suggested that, comprised 11 studies forming a large population, RASSF1A promoter methylation is significantly increased and notably common in NPC tissue samples compared with non-tissue samples, which indicated that hypermethylation of the RASSF1A promoter is closely linked to NPC tumorigenesis. In addition, they found that the pooled specificity and AUC of RASSF1A promoter hypermethylation were very good in tissue, brushing, and blood samples in the cases of NPC patients versus corresponding non-tumor samples [45]. Up to now, many studies relevant to the determination of combination many TSGs inactivated by promoter hypermethylation were carried. As the report of Kwong et al. [40], they have analyzed the promoter hypermethylation pattern of panel of eight TSGs, including RASSF1A (3p21.31), RAR $\beta 2$ (3p24.2), DAPK (9p21.33), $p 16$ (9p21.3), $p 15$ (9p21.3), $p 14$ (1q42.13), MGMT (10p26.3) and GSTP1 (11q13.2). They reported that the high frequency of promoter hypermethylation of multiple cancerrelated genes as well as at least one of eight genes showed aberrant methylation in all samples, provides an opportunity that the promoter hypermethylation may be used for the clinical diagnosis of NPC. In addition, more recent work has used next-generation sequencing (NGS) techniques, which has emerged as a powerful method to characterize the methyl changes in high resolution as well as to profile DNA hypermethylation across a whole genome or large regions of a genome, which is expected to be affordable for most research centers in the near future $[46,47]$. The advent of NGS techniques opens the possibility of discovery studies that quantify DNA methylation patterns and differences in DNA methylation could be served as potential biomarkers for the clinical diagnosis and screening of NPC.

\section{METHYLATED CIRCULATING DNA AS A NASOPHARYNGEAL CANCER BIOMARKER}

Recent advance technologies in the detection and characterization circulating tumor DNA (ctDNA) may address the great promise for the early detection and management of human cancers. Even in the early stage, ctDNA is considered to be easily detected in plasma of cancer patients $[48,49]$. In comparison to application of tissue biopsies in cancer detection, ctDNA, which fully representing tumors and is released into circulation by various pathologic and mechanism, represents a non-invasive, high specificity, sensitivity method for tumor diagnosis, and monitoring [48,50]. In addition, ctDNA could be distinguished from circulating DNA derived from healthy cells by the presence of genomic aberrant modifications [51]. The feasibility of using ctDNA in cancer detection has been demonstrated in many human cancers, including NPC. Given example, according to Wong et al., 2004, they evaluated the proposed diagnosis value of quantitative measurement of plasma DNA concentration and hypermethylated DNA markers, including panel of genes, CDH1, DAPK1, p15, p16, RASSF1A, 
Table 1: TSG located on chromosome 3 frequently hypermethylated in NPC

\begin{tabular}{|c|c|c|c|c|}
\hline Gene & Full name & Location & Functions & References \\
\hline ZMYND10 & Zinc finger MYND-type containing 10 & $3 p 21.31$ & Environmental stress-response, cell cycle progression. & {$[33-38]$} \\
\hline RASSF1A & Ras association Domain family member 1 & $3 \mathrm{p} 21.31$ & Cell cycle arrest, apoptosis, proliferation. & [39-42] \\
\hline$R A R \beta$ & Retinoic acid receptors beta & $3 p 24.2$ & Thyroid hormone receptor, transcription regulator. & {$[40,41,43]$} \\
\hline DLEC1 & Deleted in lung and esophageal cancer 1 & $3 p 21.3$ & Signaling transduction. & {$[38,44]$} \\
\hline
\end{tabular}

TSG: Tumor suppressor genes, NPC: Nasopharyngeal carcinoma

Table 2: Summary of hypermethylation status based on previous studies

\begin{tabular}{|c|c|c|c|c|c|}
\hline Gene & Reports & Sample type & Method & Patients (\%) & Controls (\%) \\
\hline \multirow[t]{5}{*}{ ZMYND10 } & Qiu et al., 2004 & Primary tumor & MSP & 66.0 & 0.0 \\
\hline & Ayadi et al., 2008 & Primary tumor & MSP & 34.1 & nd \\
\hline & Agathanggelou et al., 2003 & Tumor cell line & MSP & 80.0 & nd \\
\hline & Yau et al., 2006 & Primary tumor & qRT-PCR & 80.0 & nd \\
\hline & & Tumor cell line & & 83.3 & \\
\hline \multirow[t]{8}{*}{ RASSF1A } & Qiu et al., 2004 & Primary tumor & MSP & 74.0 & 0.0 \\
\hline & Wang et al., 2009 & Primary tumor & MSP, RT-PCR & 71.05 & 0.0 \\
\hline & & Tumor cell line & & 75.0 & \\
\hline & & Primary tumor & & 66.7 & \\
\hline & Kwong et al., 2002 & Xenograft & MSP & 100 & nd \\
\hline & & Tumor cell line & & 75.0 & nd \\
\hline & & Primary tumor & & 84.0 & 0.0 \\
\hline & Fendri et al., 2009 & Primary tumor & MSP & 91.0 & 0.0 \\
\hline \multirow[t]{2}{*}{ DLEC1 } & Ayadi et al., 2008 & Primary tumor & MSP & 86.3 & nd \\
\hline & Loyo et al., 2011 & Primary tumor & MSP & 60.4 & 3.6 \\
\hline \multirow{4}{*}{$R A R \beta$} & & Tumor cell line & & 100 & nd \\
\hline & & Primary tumor & & 81.0 & 0.0 \\
\hline & Kwong et al., 2005 & Primary tumor & MSP & 78.7 & nd \\
\hline & Fendri et al., 2009 & Primary tumor & MSP & 88.0 & 0.0 \\
\hline
\end{tabular}

nd: Not done

and $M L H 1$, in undifferentiated NPC patients. As the results, they found that methylated DNA was detectable in plasma of NPC patients, and the frequencies of $C D H 1, D A P K 1, p 15, p 16$, and $R A S S F 1 A$ were $46 \%, 42 \%$, $20 \%, 20 \%$, and $5 \%$, respectively. In contrast, the hypermethylation of MLH1 was not detected in plasma of all of the NPC patients and normal individuals. Moreover, they found that aberrantly hypermethylated promoter DNA at least one of five genes detectable in 29 of 41 (counting for $71 \%$ ) plasma of NPC patients. Thus, their results demonstrated that hypermethylated genes could be detected in the plasma of NPC patients, suggesting that hypermethylated gene might be used as a serological tumor marker in screening of primary NPC [52]. In summary, based on the circulating methylated gene promoter DNA is a possibly useful biomarker for diagnoses, prognoses, and guidance for treatments.

\section{CONCLUSION}

NPC is characterized with multiple hallmarks including the EBV infection, dietary factors, and genetic-epigenetic factors. The hypermethylation of TSG promoter, epigenetic alteration, has been shown to be a specific event that interplays during NPC initiation and progression. Measuring and detecting the hypermethylation status of TSGs derived from tissue biopsies as well as the ctDNA dynamics in body fluids such as blood, or serum is a novel area and developing research, additionally, it is considerably served as potential, great versatility and promising biomarkers for monitoring, early screening, and diagnosis of human cancers, including NPC.

\section{CONFLICTS OF INTERESTS}

The authors declared that they have no competing interests.

\section{REFERENCES}

1. Yu MC, Yuan JM. Epidemiology of nasopharyngeal carcinoma. Semin Cancer Biol 2002;12:421-9.
2. Lo KW, To KF, Huang DP. Focus on nasopharyngeal carcinoma. Cancer Cell 2004;5:423-8.

3. Thompson LD. Update on nasopharyngeal carcinoma. Head Neck Pathol 2007;1:81-6.

4. McDermott AL, Dutt SN, Watkinson JC. The aetiology of nasopharyngeal carcinoma. Clin Otolaryngol Allied Sci 2001;26:82-92.

5. Epstein MA, Achong BG, Barr YM. Virus particles in cultured lymphoblasts from Burkitt's lymphoma. Lancet 1964;1:702-3.

6. Epstein JB, Jones CK. Presenting signs and symptoms of nasopharyngeal carcinoma. Oral Surg Oral Med Oral Pathol 1993;75:32-6.

7. Tsao SW, Yip YL, Tsang CM, Pang PS, Lau VM, Zhang G, et al. Etiological factors of nasopharyngeal carcinoma. Oral Oncol 2014;50:330-8.

8. Dai W, Zheng H, Cheung AK, Lung ML. Genetic and epigenetic landscape of nasopharyngeal carcinoma. Chin Clin Oncol 2016;5:16-28.

9. Waddington $\mathrm{CH}$. The epigenotype. 1942. Int J Epidemiol 2012;41:10-3.

10. Liu M, Jiang L, Guan XY. The genetic and epigenetic alterations in human hepatocellular carcinoma: A recent update. Protein Cell 2004;5:673-91.

11. Chuang JC, Jones PA. Epigenetics and microRNAs. Pediatr Res 2007;61:24R-9.

12. Muntean AG, Hess JL. Epigenetic dysregulation in cancer. Am J Pathol 2009; 175:1353-61

13. Islam MD. Crucial challenges in epigenetic cancer therapeutic strategy yet to be resolved. Int J Pharm Pharm Sci 2016;8:1-6.

14. Esteller M. CpG island hypermethylation and tumor suppressor genes: A booming present, a brighter future. Oncogene 2002;21:5427-40.

15. Diaz LA Jr, Bardelli A. Liquid biopsies: Genotyping circulating tumor DNA. J Clin Oncol 2014;32:579-86.

16. Yuanyuan D, Haiyang Z, Haiyan L, Xiaokun L, Shulin Y. DNA methylation as an early diagnostic marker of cancer (Review). Biomed Rep 2014;2:326-30.

17. Chitakar E, Sherzay N. Epigenetics: Effect of environmental factors on human genome. Int J Pharm Pharm Sci 2016;8:1-6.

18. Bestor T, Laudano A, Mattaliano R, Ingram V. Cloning and sequencing of a cDNA encoding DNA methyltransferase of mouse cells. The carboxyl-terminal domain of the mammalian enzymes is related to 
bacterial restriction methyltransferases. J Mol Biol 1988;203:971-83.

19. Kafri T, Ariel M, Brandeis M, Shemer R, Urven L, McCarrey J, et al. Developmental pattern of gene-specific DNA methylation in the mouse embryo and germ line. Genes Dev 1992;6:705-14.

20. Le HA, Lao DT, Truong KP. DNA Hypermethylation in Breast Cancer, Breast Cancer - From Biology to Medicine, Ph.D. Phuc Pham (Ed.), InTech; 2017. p. 147-62.

21. Luczak MW, Jagodziński PP. The role of DNA methylation in cancer development. Folia Histochem Cytobiol 2006;44:143-54.

22. Kulis M, Esteller M. DNA methylation and cancer. Adv Genet 2010;70:27-56.

23. Suetake I, Shinozaki F, Miyagawa J, Takeshima H, Tajima S. DNMT3L stimulates the DNA methylation activity of DNMT3A and DNMT3B through a direct interaction. J Biol Chem 2004;279:27816-23.

24. Chen ZX, Mann JR, Hsieh CL, Riggs AD, Chédin F. Physical and functional interactions between the human DNMT3L protein and members of the de novo methyltransferase family. J Cell Biochem 2005;95:902-17.

25. Jin B, Li Y, Robertson KD. DNA methylation: Superior or subordinate in the epigenetic hierarchy? Genes Cancer 2011;2:607-17.

26. Jones PA, Laird PW. Cancer epigenetics comes of age. Nat Genet 1999;21:163-7.

27. Mossman D, Scott RJ. Epimutations, inheritance and causes of aberrant DNA methylation in cancer. Hered Cancer Clin Pract 2006;4:75-80.

28. Dai W, Cheung AK, Ko JM, Cheng Y, Zheng H, Ngan RK, et al. Comparative methylome analysis in solid tumors reveals aberrant methylation at chromosome $6 \mathrm{p}$ in nasopharyngeal carcinoma. Cancer Med 2015;4:1079-90.

29. Hui AB, Lo KW, Leung SF, Teo P, Fung MK, To KF, et al. Detection of recurrent chromosomal gains and losses in primary nasopharyngeal carcinoma by comparative genomic hybridisation. Int $\mathrm{J}$ Cancer 1999;82:498-503.

30. Lo KW, Teo PM, Hui AB, To KF, Tsang YS, Chan SY, et al. Highresolution allele type of micro dissected primary nasopharyngeal carcinoma. Cancer Res 2000;60:3348-53.

31. Lo KW, Huang DP. Genetic and epigenetic changes in nasopharyngeal carcinoma. Semin Cancer Biol 2002;12:451-62.

32. Chen J, Fu L, Zhang LY, Kwong DL, Yan L, Guan XY. Tumor suppressor genes on frequently deleted chromosome $3 p$ in nasopharyngeal carcinoma. Chin J Cancer 2012;31:215-22.

33. Cheng Y, Poulos NE, Lung ML, Hampton G, Ou B, Lerman MI, et al. Functional evidence for a nasopharyngeal carcinoma tumor suppressor gene that maps at chromosome 3p21.3. Proc Natl Acad Sci USA 1998;95:3042-7.

34. Agathanggelou A, Dallol A, Zöchbauer-Müller S, Morrissey C, Honorio S, Hesson L, et al. Epigenetic inactivation of the candidate $3 \mathrm{p} 21.3$ suppressor gene BLU in human cancers. Oncogene 2003;22:1580-8

35. Liu XQ, Chen HK, Zhang XS, Pan ZG, Li A, Feng QS, et al. Alterations of BLU, a candidate tumor suppressor gene on chromosome 3p21.3, in human nasopharyngeal carcinoma. Int J Cancer 2003;106:60-5.

36. Qiu GH, Tan LK, Loh KS, Lim CY, Srivastava G, Tsai ST, et al. The candidate tumor suppressor gene BLU, located at the commonly deleted region $3 \mathrm{p} 21.3$, is an E2F-regulated, stress-responsive gene and inactivated by both epigenetic and genetic mechanisms in nasopharyngeal carcinoma. Oncogene 2004;23:4793-806.

37. Yau WL, Lung HL, Zabarovsky ER, Lerman MI, Sham JS, Chua DT, et al. Functional studies of the chromosome $3 \mathrm{p} 21.3$ candidate tumor suppressor gene BLU/ZMYND10 in nasopharyngeal carcinoma. Int J Cancer 2006;119:2821-6.

38. Ayadi W, Karray-Hakim H, Khabir A, Feki L, Charfi S, Boudawara T, et al. Aberrant methylation of p16, DLEC1, BLU and E-cadherin gene promoters in nasopharyngeal carcinoma biopsies from Tunisian patients. Anticancer Res 2008;28:2161-7.

39. Lo KW, Kwong J, Hui AB, Chan SY, To KF, Chan AS, et al. High frequency of promoter hypermethylation of RASSF1A in nasopharyngeal carcinoma. Cancer Res 2001;61:3877-81.

40. Kwong J, Lo KW, To KF, Teo PM, Johnson PJ, Huang DP. Promoter hypermethylation of multiple genes in nasopharyngeal carcinoma. Clin Cancer Res 2002;8:131-7.

41. Fendri A, Masmoudi A, Khabir A, Sellami-Boudawara T, Daoud J, Frikha M, et al. Inactivation of RASSF1A, RARbeta2 and DAP-kinase by promoter methylation correlates with lymph node metastasis in nasopharyngeal carcinoma. Cancer Biol Ther 2009;8:444-51.

42. Wang T, Liu H, Chen Y, Liu W, Yu J, Wu G. Methylation associated inactivation of RASSF1A and its synergistic effect with activated K-Ras in nasopharyngeal carcinoma. J Exp Clin Cancer Res 2009;28:160.

43. Kwong J, Lo KW, Chow LS, To KF, Choy KW, Chan FL, et al. Epigenetic silencing of cellular retinol-binding proteins in nasopharyngeal carcinoma. Neoplasia 2005;7:67-74.

44. Loyo M, Brait M, Kim MS, Ostrow KL, Jie CC, Chuang AY, et al. A survey of methylated candidate tumor suppressor genes in nasopharyngeal carcinoma. Int J Cancer 2011;128:1393-403.

45. Ye M, Huang T, Ni C, Yang P, Chen S. Diagnostic capacity of RASSF1A promoter methylation as a biomarker in tissue, brushing, and blood samples of nasopharyngeal carcinoma. EBioMed 2017;18:32-40.

46. Laird PW. Principles and challenges of genome wide DNA methylation analysis. Nat Rev Genet 2010;11:191-203.

47. Soto J, Rodriguez-Antolin C, Vallespín E, de Castro Carpeño J, Ibanez de Caceres I. The impact of next-generation sequencing on the DNA methylation-based translational cancer research. Transl Res 2016;169:1-18.e1.

48. Leung F, Kulasingam V, Diamandis EP, Hoon DS, Kinzler K, Pantel K, et al. Circulating tumor DNA as a cancer biomarker: Fact or fiction? Clin Chem 2016;62:1054-60.

49. Han X, Wang J, Sun Y. Circulating tumor DNA as biomarkers for cancer detection. Genomics Proteomics Bioinformatics 2017;15:59-72.

50. Ignatiadis M, Dawson SJ. Circulating tumor cells and circulating tumor DNA for precision medicine: Dream or reality? Ann Oncol 2014;25:2304-13.

51. Warton K, Mahon KL, Samimi G. Methylated circulating tumor DNA in blood: Power in cancer prognosis and response. Endocr Relat Cancer 2016;23:R157-71.

52. Wong TS, Kwong DL, Sham JS, Wei WI, Kwong YL, Yuen AP. Quantitative plasma hypermethylated DNA markers of undifferentiated nasopharyngeal carcinoma. Clin Cancer Res 2004;10:2401-6. 